\title{
Globe
}

Revue internationale d'études québécoises

\section{Denyse Baillargeon, Brève histoire des femmes au Québec, Montréal, Boréal, 2012}

\section{Marie-Claude Thifault}

Volume 17, numéro 2, 2014

URI : https://id.erudit.org/iderudit/1036245ar

DOI : https://doi.org/10.7202/1036245ar

Aller au sommaire du numéro

Éditeur(s)

Globe, Revue internationale d'études québécoises

ISSN

1481-5869 (imprimé)

1923-8231 (numérique)

Découvrir la revue

Citer ce compte rendu

Thifault, M.-C. (2014). Compte rendu de [Denyse Baillargeon, Brève histoire des femmes au Québec, Montréal, Boréal, 2012]. Globe, 17(2), 214-216.

https://doi.org/10.7202/1036245ar d'utilisation que vous pouvez consulter en ligne.

https://apropos.erudit.org/fr/usagers/politique-dutilisation/ 


\section{Denyse Baillargeon \\ Brève histoire des femmes au Québec, Montréal, Boréal, 2012.}

C'est dans le format "Brève histoire", bien connu aux éditions du Boréal, que l'historienne Denyse Baillargeon, spécialiste de l'histoire des femmes, de la famille et de la santé, relève le défi d'écrire une synthèse sur l'expérience historique des femmes depuis l'époque du Régime français jusqu'à nos jours. L'exercice est complexe par l'envergure de la tâche, qui consiste à rendre compte des recherches sur l'histoire des femmes, qui se sont multipliées au cours des trente dernières années, spécifiquement depuis la publication de L'histoire des femmes au Québec depuis quatre siècles (Le collectif Clio, 1982; publiée dans une version augmentée en 1992). Longtemps un incontournable sur l'histoire des femmes, la synthèse du collectif Clio, depuis plusieurs années déjà, affiche néanmoins un contenu désuet sur plusieurs sujets. La Brève histoire des femmes au Québec remédie avec brio aux défauts que le temps a laissé voir de cette première synthèse sur l'histoire des Québécoises et propose, tant au grand public qu'aux érudits, de lire l'expérience historique des femmes basée sur les concepts et les idées-forces développés par les historiennes féministes au cours des dernières décennies selon une perspective genrée, c'est-à-dire en prenant en compte « la manière dont la féminité et la masculinité ont été conjointement et hiérarchiquement définies à différentes époques et les rapports de pouvoir hommes-femmes qui en découlent" (p. 8). Cette approche permet à Baillargeon de proposer un contenu dépassant largement le rôle des femmes au quotidien dans la sphère privée (domestique) pour également présenter les femmes en action dans la sphère publique. Cette synthèse, comme le mentionne son auteure, s'intéresse aux rôles, aux responsabilités et aux luttes des femmes selon les balises temporelles couvrant la période de la colonisation française jusqu’à la première décennie du XXI ${ }^{e}$ siècle.

Stratégiquement, cette brève histoire des femmes cherche à mettre en lumière l'expérience historique du groupe hétérogène que sont les Québécoises en faisant ressortir les forces économiques, sociales, politiques et idéologiques qui l'ont façonnée et qui permettent d'en comprendre les principales dimensions. Divisé en huit chapitres, l'ouvrage englobe les changements qui surviennent dans la société et dans la vie des femmes, précisément, en privilégiant six thèmes: les questions démographiques; l'éducation; le 
travail salarié et domestique; la religion; le droit et les rapports entre les femmes et l'État; l'action sociale et politique des femmes incluant le féminisme.

"Amérindiennes et Françaises à l'époque coloniale française» est le point de départ pour illustrer la place des femmes dans les sociétés française et autochtones. Ce premier chapitre rend compte de ce qui a peut-être été un âge d'or pour les femmes, alors qu'elles établissent les premiers réseaux de santé, d'assistance sociale et d'éducation. À ces premières initiatives, surtout mises sur pied par les communautés religieuses féminines, viennent se greffer au XIX ${ }^{e}$ siècle les activités philanthropiques des femmes qui appartiennent à la bourgeoisie marchande ou aux classes moyennes. Le deuxième chapitre, "Les débuts du Régime britannique», confirme que, loin d'être confinées à leur foyer, ces femmes occupent un rôle fondamental auprès des familles immigrantes, ou auprès de celles touchées par le chômage saisonnier ou par les épidémies. Engagé dans la voie de l'industrialisation, le Québec du milieu du XIX siècle, comme le montre le troisième chapitre, est mené par le discours social qui s'appuie sur l'idéologie patriarcale des sphères séparées et cautionne ainsi la surexploitation de la force de travail bon marché que représentent les femmes. Le chapitre suivant s'attache à la période 1880 1920, caractérisée par l'accentuation des processus d'industrialisation et d'urbanisation et par une plus large intégration des femmes sur le marché de l'emploi, en particulier lors de la Première Guerre mondiale. Les deux décennies suivantes couvrent à elles seules le contenu du chapitre cinq. Celui-ci expose l'émergence de nouveaux modèles féminins et une plus grande visibilité des femmes dans l'espace public. Elles sont également plus nombreuses à manifester pour le droit de vote et la réforme du statut juridique des femmes mariées. La période de la Deuxième Guerre mondiale jusqu'au tournant du XXI siècle, traitée dans les trois derniers chapitres de cette synthèse, illustre les profondes transformations qui animent la société québécoise et la résurgence du mouvement féministe dans la deuxième moitié du $\mathrm{XX}^{\mathrm{e}}$ siècle, qui sera néanmoins appelé à se redéfinir à l'orée du XXI ${ }^{e}$ siècle.

Cette brève histoire des Québécoises se lit rapidement parce qu'elle est bien écrite, intéressante et que la trame historique proposée est judicieuse et efficace. Au fil de la lecture, les rares doutes anticipés, concernant un sujet peut-être omis, n'ont été entretenus que le temps d'une page ou deux avant que l'auteure, avec talent, propose une réponse plus que satisfaisante à une critique émergente, aussitôt résiliée. Vraisemblablement, la contribution des Québécoises qui ont occupé des emplois dans des professions et des secteurs traditionnellement féminins a été un sujet longtemps 
boudé par les historiennes féministes. Baillargeon remédie à cette tendance en abordant celui des femmes œuvrant dans les services de santé, un sujet au cœur de ses recherches depuis plusieurs années. Le rôle des infirmières au sein de la société québécoise, par exemple, trouve sa pertinence dans cette synthèse sur l'histoire des femmes. Habilement, l'historienne participe à la déconstruction du mythe de leur servitude et fait la preuve de leur nouveau militantisme dans les des années 1960 et 1970 : un sujet clairement négligé par l'historiographie jusqu'à la fin des années 1990. Finalement, cette brillante synthèse «montre que le travail, les conditions d'existence, le statut juridique et l'engagement social et politique des femmes ne peuvent se comprendre qu'en référence à la définition sociale de la féminité, elle-même construite de manière interdépendante avec la masculinité, mais aussi à l'appartenance de classe, à l'ethnicité ou à la race qui expliquent la diversité de l'expérience historique féminine» (p. 245)... Une diversité qui retient maintenant l'attention des jeunes chercheuses et chercheurs, particulièrement en ce qui a trait à la diversité sexuelle et à la construction de genre.

Marie-Claude Thifault Chaire de recherche sur la francophonie canadienne en santé Université d'Ottawa

\section{Jean-Denis Gendron}

La modernisation de l'accent québécois. De l'accent traditionnel au nouvel accent, 1841-1960. Esquisse historique, Québec, Presses de l'Université Laval, 2014.

L'essai de Jean-Denis Gendron, La modernisation de l'accent québécois. De l'accent traditionnel au nouvel accent: 1841-1960. Esquisse historique, se présente comme un retour sur les efforts qui, à partir de 1841, ont été consentis par des éducateurs pour corriger la prononciation des Québécois. La période considérée par l'auteur commence en 1841 avec l'ouvrage correctif de Thomas Maguire, Manuel des difficultés plus communes de la langue française, adapté au jeune âge, et suivi d'un recueil de locutions vicieuses, et se termine au début des années 1960 avec la parution de son propre ouvrage correctif, Phonétique orthophonique à l'usage des Canadiens français: orthophonie, exercices de correction, textes de lecture (PUL, 1965). Sur ce plan, l'ouvrage a le mérite de rappeler à la mémoire du lecteur les personnages qui, 